\title{
Healing the system by restoring its most important virtues
}

\author{
Henk ten Have ${ }^{1} \cdot$ Bert Gordijn $^{1}$
}

Published online: 10 May 2016

(C) Springer Science+Business Media Dordrecht 2016

Asking health professionals if there are any heroes in their area of work will most likely result in diverging replies. In France they will probably mention Louis Pasteur for his discovery of micro-organisms and vaccination; in GreatBritain Joseph Lister for making surgery safe with his antiseptics. Others will refer to colleagues who changed practices; for example, Florence Nightingale or Albert Schweitzer. Identifying heroes is more common in the US than other countries. CNN is listing every year the top ten heroes, also in healthcare (CNN 2015).

The Center for Information and Study on Clinical Research Participation in Boston is running a Medical Heroes Campaign (CISCRP 2016). Volunteers participating in clinical trials are the everyday heroes who help to promote medical science. Then there are the unsung heroes who work day and night without being recognized.

\section{Osler}

For many physicians one of the uncontestable heroes of clinical medicine is William Osler, who created the first residency program at the new Johns Hopkins University in 1889. His model of bedside clinical training has become the dominant approach of graduate medical education across the world. During these clinical years not only knowledge and skills are acquired but also professional values and attitudes. This is the period shaping the values, attitudes and behaviors of young physicians. In the residency system the emphasis is on learning by doing,

\footnotetext{
Henk ten Have

tenhaveh@duq.edu

1 Pittsburgh, PA, USA
}

implementing the philosophy of John Dewey and practicing habits of thought. It is an environment where learning is a communal activity with grand rounds, morning reports, and interactive discussions. It articulates critical intellectual qualities; students should not just know what to do but, more importantly, understand why it should be done. It also articulates the moral dimension of healthcare; the patient comes first; care is a duty; health professionals need to be attentive, thorough, and empathic.

\section{Virtues}

Osler is the icon for an educational environment for generations of health professionals. He is a medical hero because he bridged in practice a gap that is often assumed in theory: the divide between science and ethics. Osler demonstrated that scientists need virtues, that specialist expertise requires moral responsibility. His view of medical education that became popular everywhere also indicated that virtue ethics is the oldest and most advocated approach in medical ethics. The moral character of health practitioners is vital for good patient care, not merely their technical and rational capabilities.

In this issue of the journal the significance of virtues is emphasized by Kotzee and Ignatowicz (2016). They discuss the importance of moral character but point out that virtues are difficult to measure. Assessment of ethics, for example in ethics education, is usually focused on measuring moral reasoning. But health professionals often need to be able to interpret experiences and meanings of critical illness and suffering. This requires self-reflection and humility since this reminds them of their own vulnerability, but it also demands virtues such as empathy and attentiveness. 


\section{Changed context of education}

Although virtues play a crucial role in healthcare, the focus on virtues does not take into account a major problem in present-day healthcare: the context of medical education is changing. In his recent book Let me heal, Kenneth Ludmerer, physician and historian of medicine, shows how residency education is eroding and disappearing (Ludmerer 2015). The overall quality of the educational environment is declining. Hospitals have developed into large medical centers delivering ever growing numbers of patient services. Stays in hospital are shortening; more and more patients are admitted. Burnout among residents has increased; the context of care has become impersonal; young physicians have less supervision; they need to focus on productivity and throughput, providing more and more service duties as a cheap labor force for the hospitals. In this context of patient care as a market commodity, speed and efficiency are paramount. The overriding goal is to discharge patients as quickly as possible. There is no time for reflection, for relationships with inspiring teachers, or for attention to patients.

\section{Learning environment}

Ludmerer concludes that "...the education of tomorrow's doctors is endangered by our country's commercialized system of health..." (Ludmerer 2015, page xii). This deterioration of the learning environment makes it increasingly difficult to articulate, practice, and reinforce virtues that are necessary for good patient care. Hospitals as service agencies precisely articulate the virtues of commercial business with physicians and nurses as patient managers and efficient providers. Unfortunately, the dominance of business virtues comes with a significant cost. The interests and rights of health care's most important stakeholders, the patients, are increasingly sidelined. In order to prevent further marginalization of patients, virtue ethicists should identify what kind of countervailing virtues are needed for contemporary health care providers. Moreover, they should justify and defend those virtues more strongly against the business virtues that are currently being promoted and enforced by most health care institutions and organizations.

\section{References}

CISCRP. 2016. Medical Heroes Campaign. https://www.ciscrp.org/ programs-events/medical-heroes/medical-heroes-campaign/.

CNN. 2015. Watch the stars come out as CNN honors its top 10 heroes. http://www.cnn.com/2015/10/08/us/cnn-top-ten-heroes$2015 /$.

Kotzee, B., and A. Ignatowicz. 2016. Measuring 'virtue' in medicine. Medicine Health Care and Philosophy 19(2): 1-13.

Ludmerer, K.M. 2015. Let me heal. The opportunity to preserve excellence in American medicine. Oxford: Oxford University Press. 